\title{
SOBRE EL ORIGEN DE LAS DEPRESIONES CIRCULARES DEL TALUD DE TRES ARROYOS, TIERRA DEL FUEGO
}

\author{
IVANA L. OZÁNª \& LUIS A. BORRERO
}

\begin{abstract}
RESUMEN
Desde un abordaje geoarqueológico, este trabajo se propone discutir detalladamente el origen de las depresiones circulares ubicadas en el talud del Cerro de los Onas, localidad de Tres Arroyos. Algunos trabajos previos interpretaron dichas depresiones como improntas de viviendas plurifamiliares Selk'nam, basándose en resultados de algunas excavaciones, similitudes morfo-métricas con las descripciones etnográficas y contrastes de vegetación dentro y fuera de la depresión. Sin embargo, en esta investigación se sostiene el origen natural de estos rasgos en base a la ausencia de diferencias en el tipo y frecuencia de materiales antrópicos dentro y fuera de las depresiones, la existencia de depresiones sin materiales antrópicos en Tres Arroyos y otras localidades del norte de la Isla y los mayores valores de susceptibilidad magnética registrados en toda el área de mayor concentración de materiales, independientemente de si se trate de sectores dentro o fuera de las depresiones. Los indicadores sedimentarios y micromorfológicos tampoco mostraron contrastes acentuados dentro y fuera de las depresiones. Finalmente se plantea como hipótesis alternativa que el origen de las depresiones podría estar relacionado con procesos de deflación eólica tras la muerte de arbustos; o bien, con revolcaderos de guanacos y/u ovejas.
\end{abstract} animales.

PALABRAS CLAVE: cerro de los Onas, Holoceno tardío, geoarqueología, revolcaderos de

\section{ABOUT THE CIRCULAR DEPRESSION ORIGIN PLACED ALONG THE TRES ARROYOS TALUS, TIERRA DEL FUEGO}

\footnotetext{
ABSTRACT

From a geoarchaeological frame, this work aims to discuss the origin of some circular depressions placed along the Cerro de los Onas talus, at Tres Arroyos archaeological locality. Previous research

a Instituto de Geociencias Básicas, Aplicadas y Ambientales de Buenos Aires, Consejo Nacional de Investigaciones Científicas y Tecnológicas (CONICET). Departamento de Ciencias Geológicas, Universidad de Buenos Aires, Pabellón 2, Ciudad Universitaria (C1428EGA), Buenos Aires, Argentina. $>$ ivanalozan@gmail.com

b Instituto Multidisciplinario de Historia y Ciencias Humanas, CONICET. Saavedra 15, Piso 5 (1083ACA) Buenos Aires,

Argentina. laborrero2003@yahoo.com
} 
proposed that those features could have been related with related with Selk'nam hut imprints, mainly based on ethnographic descriptions, buried record and vegetation contrasts inside and out of the depressions. However, the present work supports a natural origin of the circular depressions due to the lack of archaeological contrasts (type/ frequency of the record and the magnetic susceptibility signal) in test pits carried out inside and outside the features. Additionally, the presence of depressions without archaeological remains at Tres Arroyos and other localities of the regions also support their natural origin. Indeed, sedimentological and soil micromorphological data do not indicate clear differences between depressions and adjacent areas. It is finally proposed as an alternative hypothesis that the circular depressions could be a consequence of wind deflation in shrub hollows or sheep/guanaco abandoned grass wallows.

KEY WORDS: cerro de los Onas, late Holocene, geoarchaeology, grass animal-wallows.

\section{INTRODUCCIÓN}

La localidad arqueológica Tres Arroyos (TA) se ubica en el centro-norte de Tierra del Fuego, Chile (Fig. 1). El Cerro de los Onas (S53 $21.693^{-} \mathrm{W}^{\circ} 68^{\circ} 47.817^{\prime}$ ) ha sido el foco principal de las investigaciones arqueológicas de la localidad, que comenzaron hace más de 30 años abordando múltiples líneas de evidencia (e.g. Laming-Emperaire et al. 1972; Saxon, 1979; Massone et al. 1993; Arroyo \& Jackson, 1998; Borrero, 2003; Massone, 2004; Martin, 2006; Prevosti, 2006). Los trabajos realizados en torno al Cerro de los Onas en 13 aleros, una cueva y a lo largo del talud mostraron que este espacio fue ocupado tempranamente, en plena transición Pleistoceno-Holoceno y cuando Tierra del Fuego aún estaba unida al continente. En ese momento las poblaciones coexistieron con fauna extinta, e incluso la aprovecharon como alimento, aunque la evidencia muestra que de un modo no intensivo, siendo el guanaco la presa principal. No se han encontrado evidencias arqueológicas correspondientes al Holoceno medio, mientras que las ocupaciones durante el Holoceno tardío y hasta tiempos históricos muestran redundancia ocupacional. Asimismo, para estos últimos milenios, la evidencia arqueológica indica que este espacio se encontraba integrado en una región más amplia, abarcando sectores litorales, dada la presencia de valvas de moluscos marinos, y sectores más septentrionales, a partir de la presencia de materia prima proveniente de Chorrillo Miraflores (Prieto et al. 2004).

En los taludes norte, noreste y este del Cerro de los Onas se registraron más de 300 depresiones circulares/subcirculares, algunas de las cuales fueron interpretadas como improntas de viviendas plurifamiliares Selk'nam, ocupadas de modo no sincrónico para momentos históricos (Fig. 2). En principio, esta afirmación se basó en las similitudes morfo-métricas de estas depresiones $(2,10-4,95 \mathrm{~m}$ de diámetro y $5-21 \mathrm{~cm}$ de profundidad) respecto a aquellas descriptas etnográficamente (e.g. Gallardo, 1910; Dabbene, 1911; Gusinde, 1982 [1931]). La mayor abundancia de registro arqueológico en capa dentro de las dos depresiones sondeadas (restos óseos, líticos, pigmentos y evidencias de combustión) sumado a la predominancia del arbusto Azorella trifurcata (interpretado como consecuencia del enriquecimiento en materia orgánica por acción antrópica) permitieron afirmar que las depresiones en cuestión fueron utilizadas como viviendas (Massone et al. 1993; Massone, 2004).

Sin embargo, algunos sondeos $y$ excavaciones realizadas dentro de estos rasgos, tanto en TA como en loci aledaños, no registraron materiales antrópicos, por lo que Massone et al. (1993) plantearon que las depresiones de TA podrían ser: 1) producto de la acción antrópica; 2) naturales y luego aprovechadas como viviendas; o 3) naturales no aprovechadas por las poblaciones. Pese a que trabajos posteriores continuaron interrogando el carácter antrópico de estos rasgos (Borrero, 2003), aún persiste cierta ambigüedad acerca de su naturaleza (Oría, 2014), por lo tanto, desde un abordaje geoarqueológico, el objetivo de este trabajo es discutir detalladamente el origen de estas depresiones circulares del talud de TA. 


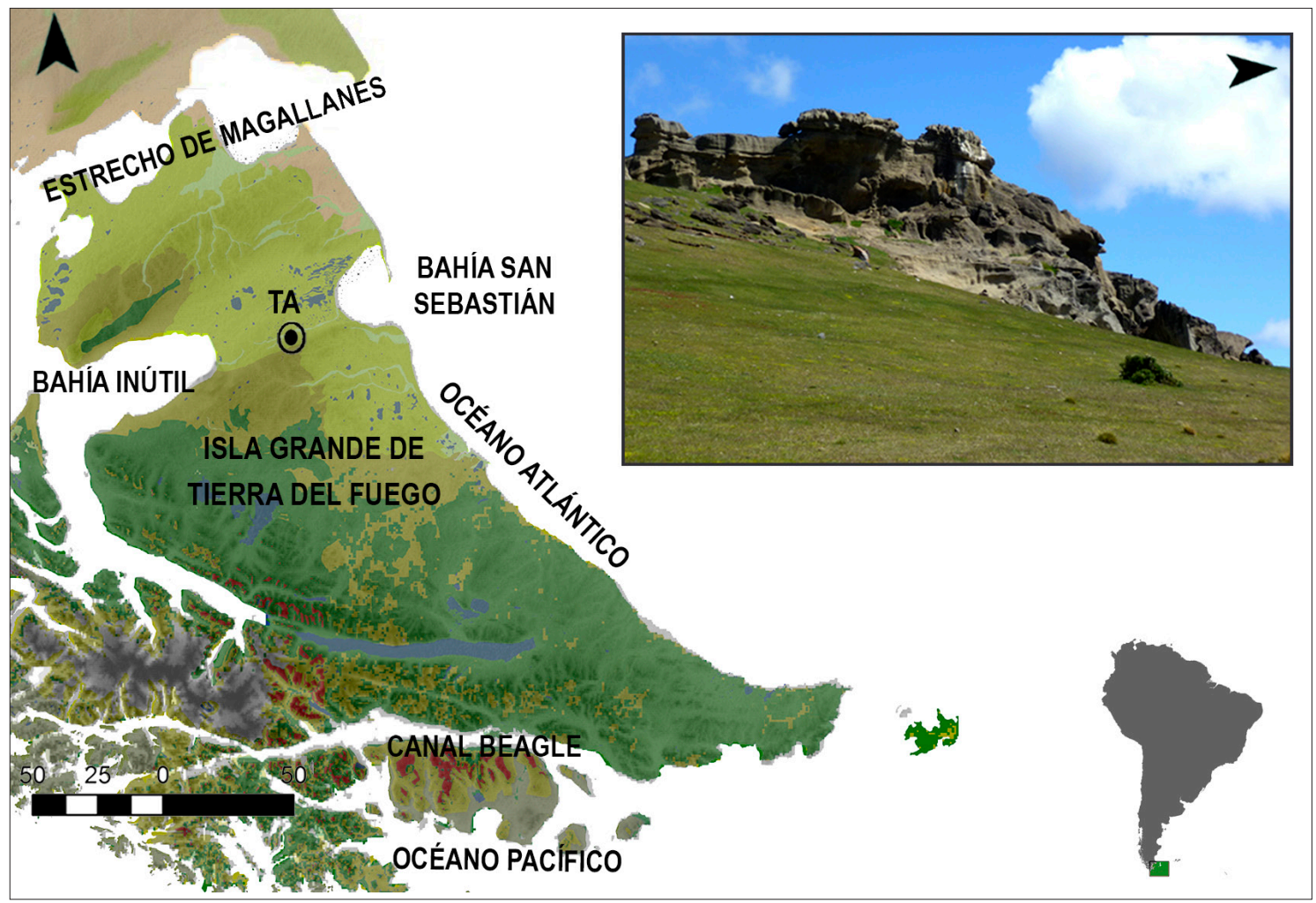

Fig. 1. Ubicación de la localidad de Tres Arroyos (TA) y vista panorámica del Cerro de los Onas.

El área de estudio

La localidad bajo estudio se ubica en una zona de serranías bajas, cercanas a la depresión que conecta Bahía San Sebastián (Océano Atlántico) y Bahía Inútil (Océano Pacífico) (Coronato, 2014) (Fig. 1). Específicamente el Cerro de los Onas, se encuentra próximo a uno de los pocos ríos permanentes de la región, el río San Martín. El área se caracteriza por un clima marítimo (baja amplitud térmica anual y diaria), con temperaturas medias anuales de unos $5 / 6^{\circ} \mathrm{C}$ y precipitaciones menores a los $400 \mathrm{~mm}$ anuales. En conjunto, estas condiciones determinan un clima semiárido, con vientos intensos del cuadrante oeste/ sudoeste que soplan a un promedio de $40 \mathrm{~km} / \mathrm{h}$, llegando a $60 \mathrm{~km} / \mathrm{h}$ en los meses de verano, con ráfagas que pueden superar los $180 \mathrm{~km} / \mathrm{h}$ (Vilas et al. 1986/87; Frederiksen, 1988; Coronato \& Bisigato, 1998; Dirección Meteorológica de Chile, 2008). Fitogeográficamente, se clasifica a esta región dentro de la estepa patagónica o magallánica con un predominio de matas áfilas, especies en cojín y gramíneas; y un débil desarrollo edáfico (Pisano, 1977; Frederiksen, 1988; Soil Survey Staff, 1999; Allue et al. 2010).

\section{METODOLOGÍA}

El diseño metodológico dirigido a evaluar la naturaleza de las depresiones del talud de TA se basó en analizar comparativamente las propiedades físico-químicas tanto de las depresiones en sí mismas, como de las áreas adyacentes a ellas, a fin de poder indagar génesis y transformación de dichas propiedades. A su vez, el muestreo de las depresiones y áreas adyacentes se distribuyó en sectores con mayor abundancia relativa de registro arqueológico y otros sectores con ausencia o escasez de dicho registro. Con este criterio, se llevó a cabo un total de ocho sondeos (ver ubicación en Fig. 3), de 50x25 cm los primeros $20 \mathrm{~cm}$ de profundidad y luego de $25 \times 25 \mathrm{~cm}$ hasta unos 40-60 cm de profundidad, dependiendo de 


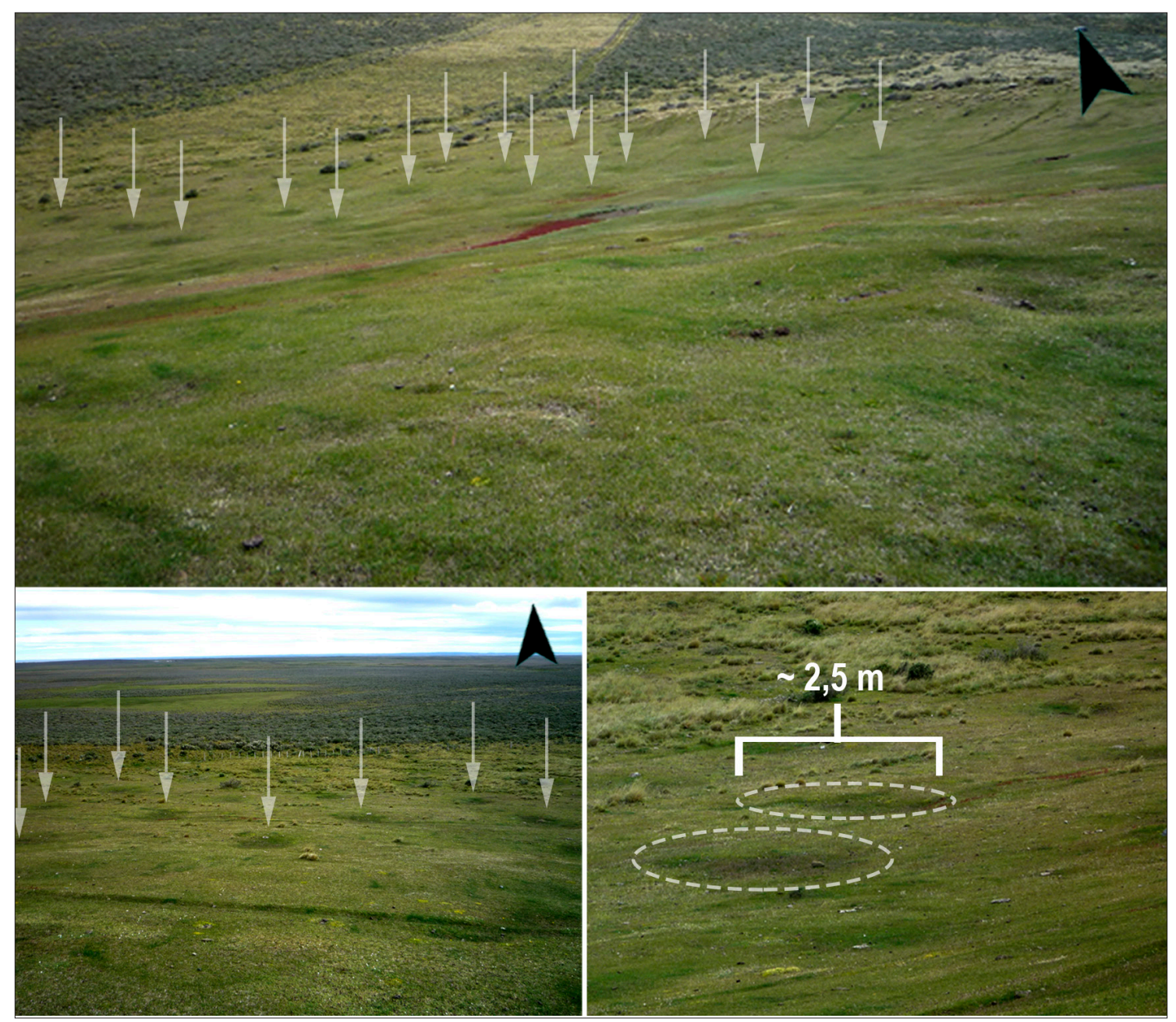

Fig. 2. Vista de las depresiones circulares del talud norte/noreste de TA.

la presencia de material arqueológico (se dejó de profundizar luego de $10 \mathrm{~cm}$ sin presencia de registro). La excavación fue por niveles artificiales de $10 \mathrm{~cm}$ de espesor y los sedimentos se tamizaron en seco, con malla de $2 \mathrm{~mm}$.

En cada perfil de los sondeos se realizaron descripciones macroscópicas de los horizontes de suelo (A-AC-C o A-C) y se tomaron muestras de cada uno de los mismos. En algunos casos también se extrajeron muestras estructuradas para análisis micromorfológicos. Para la comprensión de la información edafológica y sedimentaria se elaboró un mapa geomorfológico a escala local a partir de la información previa, imágenes satelitales (Google $\operatorname{Earth}^{\circledR}$ ), fotos aéreas y observaciones de campo.

Los horizontes de suelo se describieron siguiendo algunos parámetros convencionales como espesor, color en seco, textura, límite, estructura, presencia de moteados, concreciones, bioactividad, humedad, compactación y presencia de grietas de desecación (e.g. Fitzpatrick, 1976; Birkeland, 1999; Soil Survey Staff, 1999). Las muestras para análisis micromorfológicos se tomaron sin disturbar los sedimentos (prismas de unos $7 \times 10 \mathrm{~cm}$ ), fueron secadas a temperatura ambiente, impregnadas con resinas poliéster, montadas sobre un portaobjetos y pulidas hasta los 25/30 $\mu \mathrm{m}$. Las láminas delgadas resultantes fueron observadas con un microscopio petrográfico de luz blanca polarizada, con lentes de 4x, 10x y 63x y oculares de 10x. La descripción se realizó siguiendo protocolos internacionales (Bullock et al. 
1985; Stoops, 1986, 2003; Stoops et al. 2010). A partir de los mismos cortes delgados se analizó la mineralogía y los componentes antropogénicos (siguiendo a Ozán et al. 2015).

Los estudios granulométricos fueron realizados por sedígrafo (Sedigraph Malvern) y la fracción grava (>2 mm) se separó con tamiz. Adicionalmente se midió pH (con SANXIN model PHS-3D-02), carbonatos (por titulación alcalimétrica con ácido clorhídrico como titulante) y la susceptibilidad magnética (con un Magnetic Susceptibility Meter Bartington MS2, valores normalizados a masa), para explorar de forma indirecta procesos de combustión (Dalan \& Banerjee, 1998).

\section{RESULTADOS}

La Fig. 3 muestra el mapa geomorfológico del área de TA donde puede verse el cauce del río San Martín, su planicie de inundación, sectores de paleo-planicies y paleo-cauces. Existe un claro predominio de geoformas fluviales, responsables del retrabajo de depósitos glaciares. El talud del cerro se encuentra estabilizado por una espesa cobertura vegetal y no se observan caídas de bloques recientes. Las pendientes del talud norte/ noreste, presentan: un sector superior con una pendiente que alcanza los $18^{\circ}$; un sector medio con una pendiente inferior a los $16^{\circ}$; y el sector bajo que es prácticamente plano, entre $24^{\circ}$.

La Fig. 4 y Tabla 1 (en Anexo) sintetizan las principales características de los perfiles realizados. En términos generales, se observan suelos muy pobremente desarrollados, es decir, con poca diferenciación de horizontes (A-AC-C o A-C). Los análisis micromorfológicos (Tabla 2, en Anexo) señalan microestructuras granulares como producto de la bioturbación de meso/macro fauna de suelo y raíces, aunque procesos relacionados con ciclos de congelamiento/ descongelamiento (Bertran \& Texier, 1999; French, 2007) y argiloturbación (por arcillas expansibles) también podrían influir en esta microestructura (Fig. 5A). En todos los casos existe un predominio de las fracciones más finas $(<50$ $\mu \mathrm{m})$, aunque con variaciones inter/ intra-sondeo. Se registra un importante componente eólico en todas las muestras (partículas de feldespato potásico y cuarzo en menor medida, subredondeados/ subangulares, fracción arena fina/ limo grueso), asociado y mezclado en distintas proporciones con material coluvial (líticos de tamaño grava y arena gruesa provenientes de la roca de caja). La buena preservación de las trizas volcánicas sugiere altas/ moderadas tasas de sedimentación (Fig. 5B). En casi todos los casos, a nivel microscópico, la disposición de las arcillas en la matriz del suelo (como por ejemplo revistiendo perimetralmente partículas y poros) estaría sugiriendo procesos de iluviación moderados y regulares (Fig. 5C). Un análisis detallado de la porosidad microscópica de la matriz fue realizado con JMicroVision v1.2.7. (Fig. 5E).

De este análisis digital se desprende que los suelos en las depresiones son, en promedio, algo más porosos respecto a las áreas adyacentes. Asimismo, el tipo de porosidad también es contrastante entre ambas áreas, hecho que se podría interpretar como consecuencia de mayor bioactividad y/o humedad en las depresiones, dos rasgos que a su vez se vinculan. Finalmente, cabe señalar que la evidencia micromorfológica no indica de ningún modo la presencia de un cuerpo de agua.

La Fig. 6 resume la proporción relativa de los minerales predominantes cuantificados a partir de las secciones delgadas. En términos generales abundan feldespatos potásicos, óxidos de $\mathrm{Fe} / \mathrm{Mn}$ en forma de nódulos e impregnaciones, plagioclasas y líticos constituidos mayormente por las areniscas provenientes de la meteorización del alero (con cemento de óxidos de Fe/Mn y partículas representadas principalmente por rocas volcánicas, anfíboles y piroxenos), seguidas por rocas volcánicas y metamórficas. En menor proporción se observa cuarzo, anfíboles, minerales opacos y piroxenos. Vale destacar que en S2, S4 y S6 se registran trizas volcánicas. Si bien a nivel intra-sondeo existen cambios en las frecuencias de minerales, el tipo se mantiene constante, sugiriendo pocos o nulos cambios de las áreas de aporte. En suma, esta información mineralógica no sugiere la presencia de discordancias erosivas.

En promedio, los sedimentos van de limo medio a arena fina y son pobre/muy pobremente seleccionados (Tabla 1 en Anexo). Esto último indica que existen varios agentes de sedimentación y/o el agente predominante es de baja selectividad. 


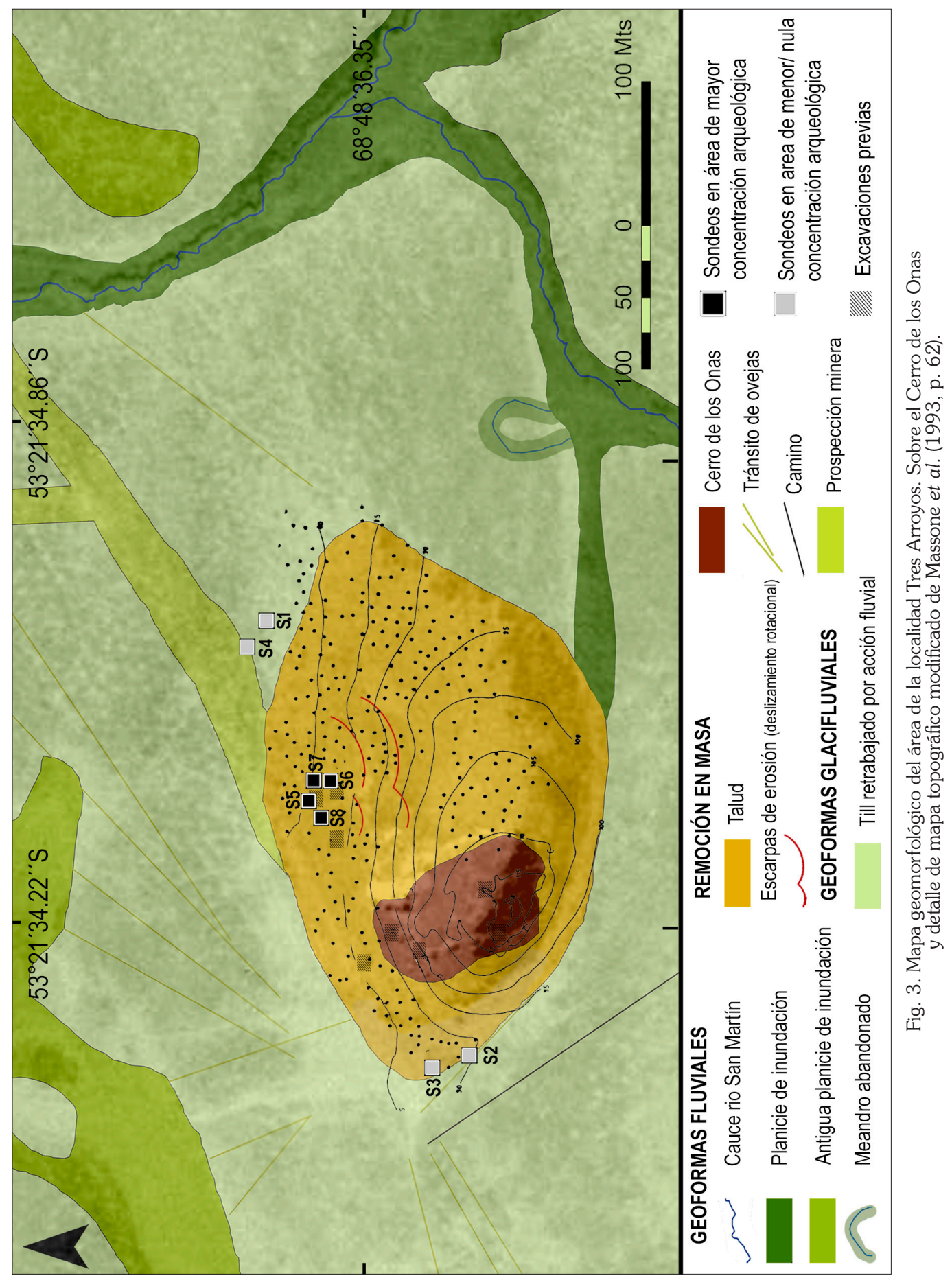



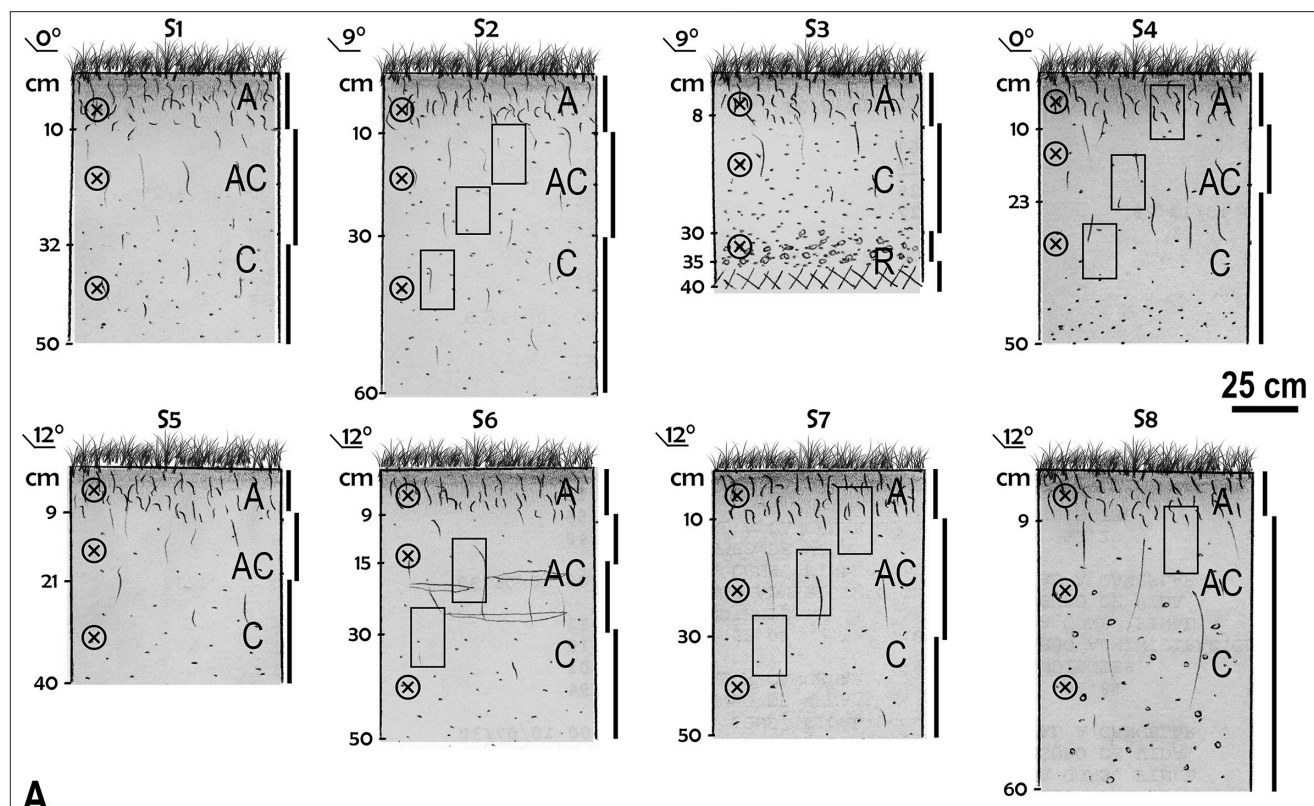

A

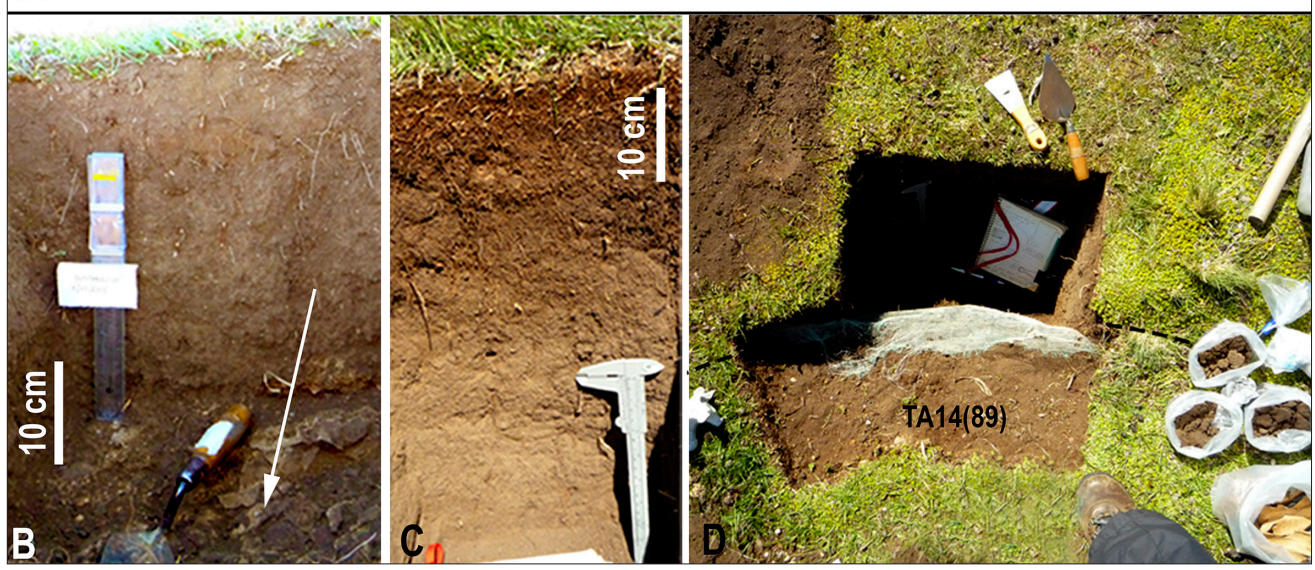

Fig. 4. A- Esquemas a escala de los sondeos. Las cruces señalan la posición de la toma de muestras no estructuradas y los rectángulos la posición de las muestras para análisis micromorfológicos. Ejemplos de perfiles: B) S3 en cuya base aflora la roca de caja. C) S7, nótese la escasa diferenciación de horizontes con límites difusos. D) Planta de S6, sondeo ubicado en el sector exterior de la "impronta TA14(89)" (sensu Massone et al. 1993).

El caso de S6 -fuera de la depresión- destaca por poseer un mayor porcentaje de arcilla $(13,8 \%)$; mientras que en el otro extremo $-\mathrm{y}$ pese a su proximidad espacial- se encuentra S8 -dentro de la depresión- (5,4\%). Finalmente, la cuantificación de la fracción grava en todos los sondeos indica valores que van entre $0,5-17 \%$ (sin considerar el de $35,5 \%$ de S3 que en realidad se trata de regolito).

Respecto a los datos geoquímicos y magnéticos, se observa que, en promedio, el $\mathrm{pH}$ es levemente ácido (5.7-6.3), datos que resultan consistentes con los bajos valores de carbonatos $(<1,1 \%$; Tabla 1 en Anexo). Por su lado, los valores de susceptibilidad magnética muestran que la misma aumenta levemente en profundidad. No parecen existir tendencias entre los sondeos ubicados en las depresiones, por un lado, y en áreas adyacentes a las mismas, por otro, pero sí se observa que en los sondeos ubicados en el área de mayor abundancia de registro arqueológico los valores son más altos (Tabla 1 en Anexo). En suma, toda esta información no muestra contrastes 


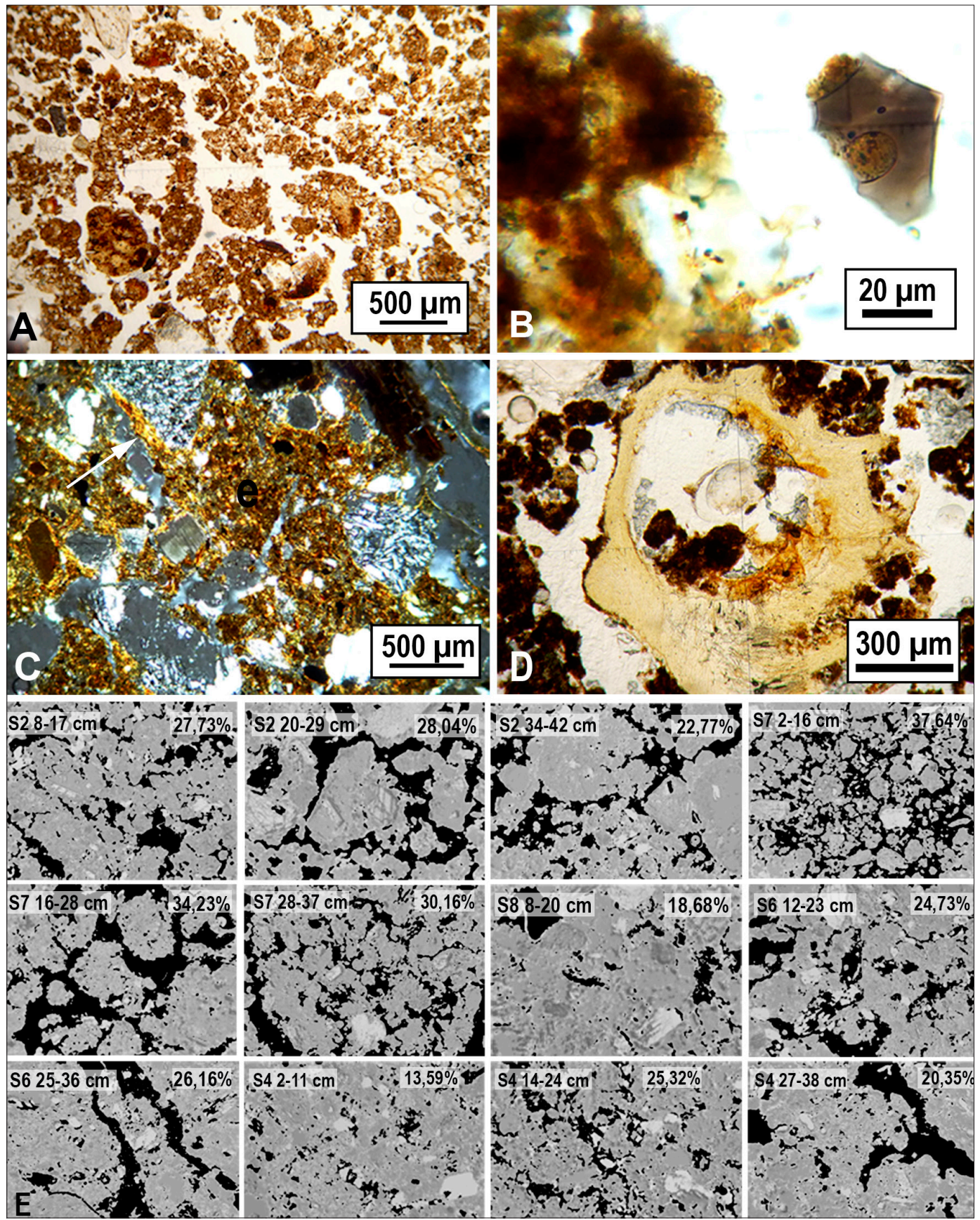

Fig. 5. Microfotografías de las láminas delgadas ( $\mathrm{PPL}=$ sin nicoles; XPL $=$ con nicoles). A- Microestructura que muestra rasgos de bioactividad y/o ciclos de congelamiento/ descongelamiento y/o expansión/ contracción de arcillas (PPL; S7 16-28 cm). B- Fragmento de triza volcánica bien preservada (PPL; S2 20-29 cm). C- La flecha señala ciertos rasgos brillantes correspondientes a dominios de arcillas bien orientadas, como producto de una iluviación paulatina y cíclica de esta fracción fina (XPL; S6 12-23 cm). D- Fragmento óseo con revestimiento perimetral de material fino mezclado con materia orgánica, interpretable como posición de "estabilidad"; precipitación de óxidos de Fe al interior; presencia de canales por ataque bacteriano (PPL; S2 8-17 cm). E- Cuantificación del porcentaje del área poral (en negro); microfotografías tomadas con lente 10x, a excepción de las muestras de S7, tomadas en 4x (JMicroVision v.1.2.7.). 


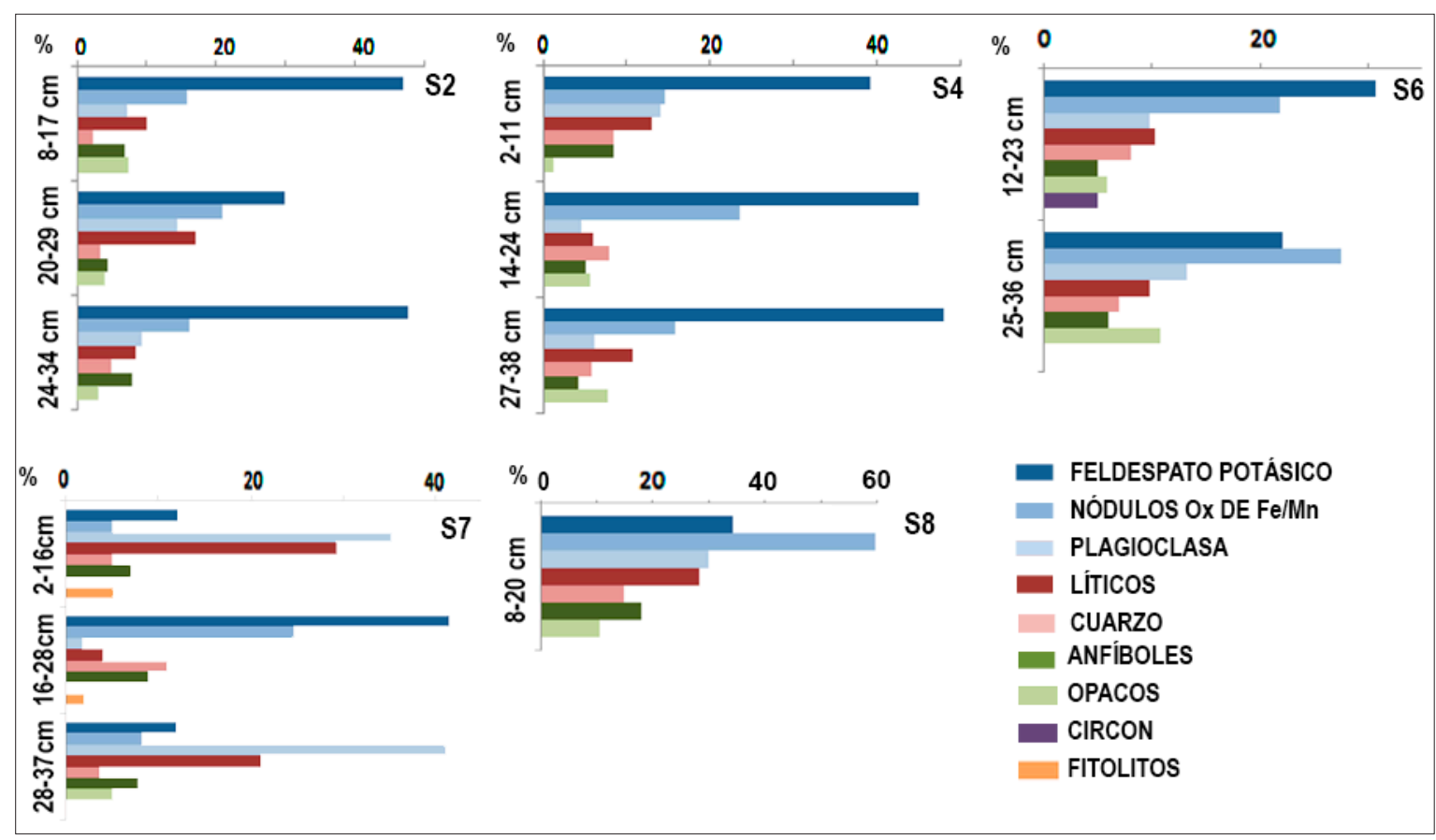

Fig. 6. Frecuencias relativas de los minerales registrados en las secciones delgadas.

nítidos respecto a las propiedades físico-químicas registradas en las depresiones y las áreas adyacentes a ellas. La Tabla 1 sintetiza comparativamente las principales características sedimentarias de los sondeos analizados.

\section{Registro arqueológico}

Los materiales arqueológicos recuperados en los sondeos comprenden restos óseos, desechos líticos, espículas de carbón y pequeños fragmentos de pigmento rojo. Las frecuencias verticales absolutas de estos materiales son mayores entre los $10-30 \mathrm{~cm}$ de profundidad, aunque no existe una tendencia acentuada. La Fig. 7 ilustra las frecuencias de artefactos líticos, restos óseos (NISP) y espículas de carbón.

Dentro de los desechos indiferenciados de roca silicificada destacan dos de vidrio transparente (europeo) en S7 $(0-10 \mathrm{~cm})$ y en S5 $(10-20 \mathrm{~cm})$. El conjunto óseo se encuentra representado principalmente por restos de roedor, seguido por guanaco, oveja y algunos ejemplares de ave en S7 y S8. En S7 $(20-30 \mathrm{~cm})$ también se hallaron dos pequeños fragmentos de valva, en mal estado.
Entre los huesos de roedor cabe señalar el caso de fragmentos quemados en S6 $(10-20 \mathrm{~cm})$ y S7 $(20-$ $30 \mathrm{~cm})$; y la presencia de marcas de raíces sobre huesos de guanaco en S7 $(0-20 \mathrm{~cm})$ y S8 $(20-30$ $\mathrm{cm})$ (Borrero, 2013).

En relación a los componentes antropogénicos observados en las secciones delgadas de micromorfología de suelos (Fig. 5 y 7), en las muestras de S7 y S8 se registran las mayores frecuencias de los mismos, situación consistente con los hallazgos macroscópicos cuantificados en los mismos sondeos. Sin embargo, las frecuencias son mayores en las muestras que corresponden a perfiles dentro de las depresiones, pero las diferencias en el muestreo dificultan la comparación. Los micro-fragmentos óseos muestran grados de meteorización variables, indicando una depositación diacrónica y/o mezcla de los depósitos (naturales y antrópicos). La excelente preservación de algunos carbones en S8 podría estar indicando baja o nula migración vertical y/u horizontal de los mismos.

Por lo tanto, fuera del área de mayor concentración arqueológica (S1, S2, S3, S4), las frecuencias de restos óseos y los escasos desechos líticos son más abundantes en las 
Tabla 1. Síntesis comparativa, de acuerdo a la ubicación, de las principales características sedimentológicas de los sondeos analizados. Ver Tabla 1 y 2 de Anexo para una información detallada de la información.

\begin{tabular}{|c|c|c|}
\hline & $\begin{array}{c}\text { EN ÁREA DE CONCENTRACIÓN DE MATERIALES } \\
\text { ARQUEOLÓGICOS }\end{array}$ & $\begin{array}{c}\text { EN ÁREAS FUERA DE LA CONCENTRACIÓN DE } \\
\text { MATERIALES ARQUEOLÓGICOS }\end{array}$ \\
\hline 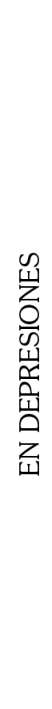 & $\begin{array}{l}\text { S7 Sedimento castaño grisáceo, franco-limoso, } \\
\text { estructuración fuerte, } 0-1 \% \text { grava, }<1 \% \text { carbonatos, } \mathrm{pH} 6.3 \text {, } \\
\text { susc. mag.: } \sim 29 \times 10^{-7} \mathrm{~m}^{3} / \mathrm{kg} \text {. Micromorfología: Porosidad: } \\
\text { 10-30\%. Materia orgánica: <15\%. Moderados procesos de } \\
\text { iluviación. Micro-carbones y restos óseos quemados. } \\
\text { Depositación coluvial y é́lica. Predominio de feldespatos } \\
\text { potásicos, líticos, óxidos de Fe/Mn y plagioclasas. } \\
\text { S8 Sedimento castaño grisáceo, franco-limoso, } \\
\text { estructuración fuerte, } 7-8 \% \text { grava, pH } 6 \text {, susc. mag.: } \\
\sim 28 \times 10^{-7} \mathrm{~m}^{3} / \mathrm{kg} \text {. Micromorfología: Porosidad: 20-25\%. } \\
\text { Materia orgánica: <10\%. Moderados procesos de iluviación. } \\
\text { Depositación coluvial. Micro-carbones y restos óseos } \\
\text { quemados. Predominio de óxidos de Fe/Mn, feldespatos } \\
\text { potásicos y plagioclasas. }\end{array}$ & $\begin{array}{l}\text { S1 Sedimento castaño grisáceo, franco-limoso, } \\
\text { estructuración fuerte, } 2-3 \% \text { grava, }<1 \% \text { carbonatos, susc. } \\
\text { mag.: } \sim 21 \times 10^{-7} \mathrm{~m}^{3} / \mathrm{kg} \text {. } \\
\mathrm{S} 2 \text { Sedimento castaño grisáceo, franco-limoso, } \\
\text { estructuración fuerte, } 8-9 \% \text { grava, <1\% carbonatos, pH } \\
6.2 \text {, susc. mag.: } \sim 18 \times 10^{-7} \mathrm{~m}^{3} / \mathrm{kg} \text {. Micromorfología: } \\
\text { Porosidad: } 20-30 \% \text {. Materia orgánica: <20\%. Escasos } \\
\text { procesos de iluviación. Depositación coluvial. Escasos } \\
\text { micro-fragmentos óseos, algunos calcinados. Predominio } \\
\text { de feldespatos potásicos, óxidos de Fe/Mn y plagioclasas. }\end{array}$ \\
\hline
\end{tabular}

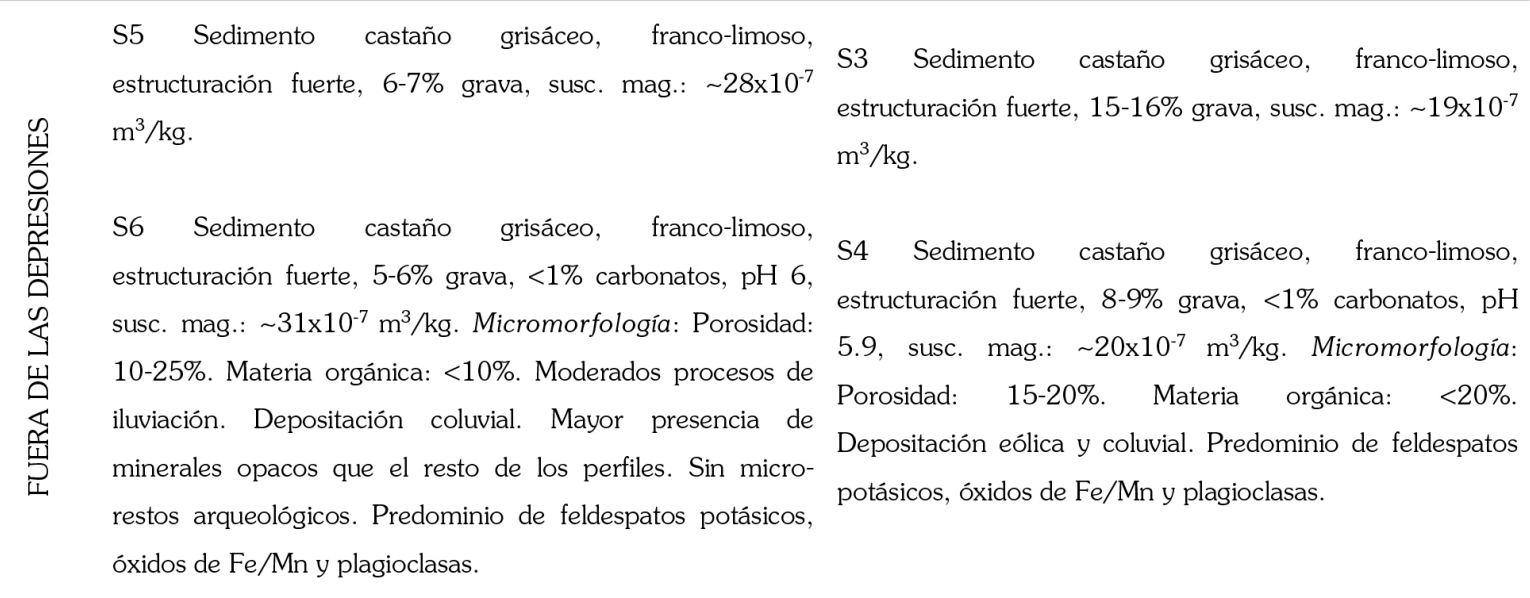

depresiones respecto a las áreas adyacentes a ellas. Por otro lado, en el área de mayor concentración de restos arqueológicos, se observa que en las depresiones hay más restos óseos que en las áreas adyacentes, ocurriendo lo contrario con los artefactos líticos y las frecuencias de espículas de carbón y "pigmento rojo" que aparecen en toda la extensión del Cerro de los Onas. La distribución vertical de las frecuencias del registro macro y microscópico es de tipo unimodal, con moda en el horizonte transicional AC, entre los $\sim 10-30 \mathrm{~cm}$ de profundidad. La excepción del caso S8, que presenta un segundo incremento de materiales óseos entre los 30-40 cm, podría desestimarse de la evaluación ya que una de las subas incluye la cuantificación de un conjunto óseo compuesto enteramente por huesos de roedor sin marcas de combustión, o sea, probablemente no asociados a las ocupaciones humanas. 


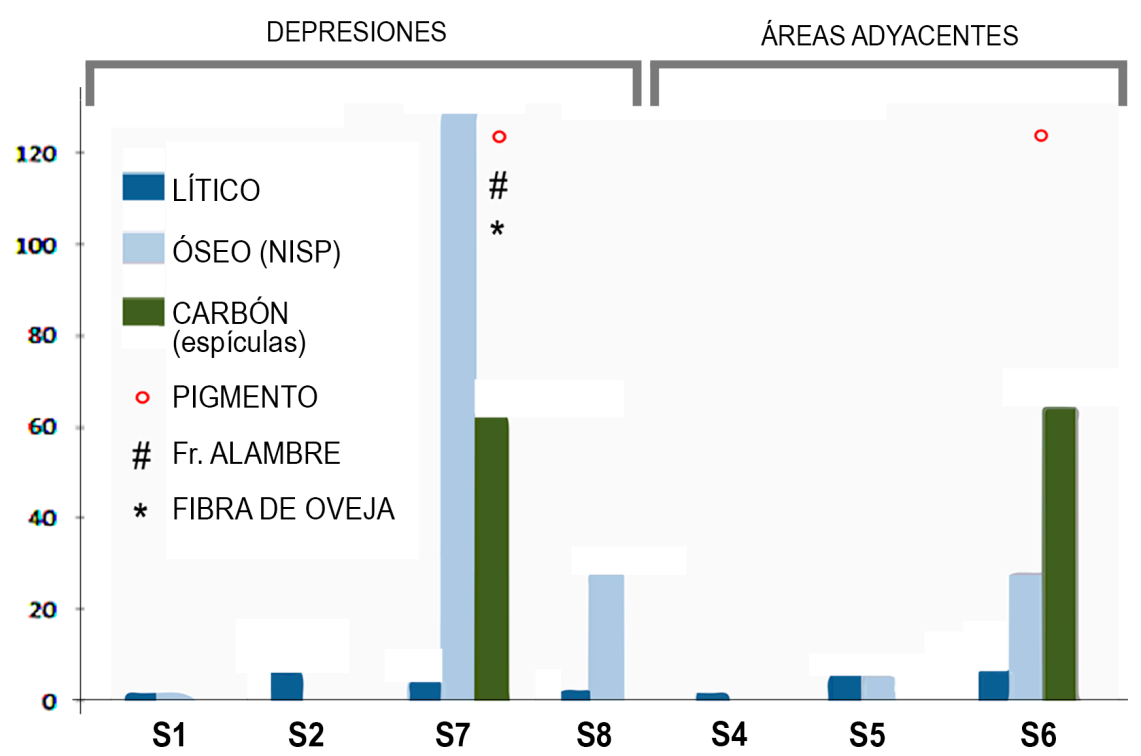

Fig. 7. Frecuencia absoluta de materiales arqueológicos dentro y fuera de la depresión.

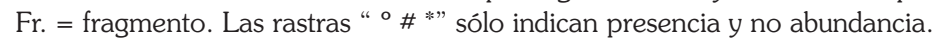

\section{DISCUSIÓN}

La asignación de un origen antrópico a las depresiones circulares/ subcirculares de TA (Massone et al. 1993; Massone, 2004), o más específicamente su interpretación como huellas de viviendas de un extenso campamento Selk'nam para tiempos post-contacto, ya ha sido puesta en tela de juicio en otros trabajos, señalando la ausencia de material arqueológico en muchas de estas marcas (Borrero, 2000, 2003). Asimismo, en $\mathrm{TA} 14(30)$ se reconocen al menos dos acumulaciones óseas: una superior (arqueológica) datada en 2280 \pm 60 BP (Beta-101055) y otra inferior (paleontológica) datada en 12280 $110 \mathrm{BP}$ (Beta-101056) (Borrero, 2003). En el mismo lugar se dataron huesos de guanaco "modernos" (LP883), mostrando la existencia de migración vertical de material óseo y la presencia de depresiones no vinculadas a ocupaciones humanas (Borrero, 2000, 2003).

La discusión acerca de su origen tiene un efecto en la arqueología de Magallania insular, en tanto la adscripción de este locus como un gran campamento lo vuelve un área nodal (Oría, 2014), como el sur de Bahía San Sebastián (localidad Chorrillos), la costa de Bahía Inútil (localidad Marazzi y Bahía Inútil) y la costa del Estrecho de Magallanes (localidades Cabo San Vicente, Punta
Baxa y Punta Catalina) (Horwitz, 1995; Massone, 1997; Morello et al. 1999, 2012; Massone et al. 2003; Martin et al. 2004; Massone \& Torres, 2004; Morello et al. 2005; Massone \& Morello, 2007; Borrero et al. 2006; Torres, 2009; Pallo, 2012; Borrazzo, 2014).

De acuerdo a la información obtenida desde una perspectiva geoarqueológica, aquí se plantea que las 304 depresiones distribuidas por el talud medio e inferior no serían el resultado de las huellas dejadas por el establecimiento de chozas Selk'nam en tiempos históricos, por los argumentos que se enumeran abajo.

1- Depresiones sin registro arqueológico. De las 20 depresiones sondeadas por los autores, 14 mostraron material arqueológico, cuatro materiales dudosos y dos no presentaron registro. Adicionalmente, en otra depresión excavada sólo se halló una corurera y restos de un guanaco sin evidencia de acción humana con una datación de más de 2000 años AP (Borrero, 2000, 2003). A unos pocos kilómetros al norte del Cerro de los Onas, se registró otra concentración de materiales arqueológicos (TA6) y unas 60 depresiones circulares/subcirculares de 2-4 m de diámetro. Los únicos dos sondeos ubicados en estos rasgos sólo mostraron 
restos de guanaco y oveja hasta los $15 \mathrm{~cm}$ de profundidad (Massone et al. 1993). En Estancia Dos Marías y Florentina (a unos 30 $\mathrm{km}$ al norte de TA) también se observaron estos rasgos, aunque con algunas diferencias microtopográficas respecto a los de TA. Unos 12 sondeos realizados en su interior no hallaron materiales arqueológicos (Massone et al. 1993). Finalmente, en depresiones similares observadas en Laguna Cañadón Piedra, sobre una suave pendiente, tampoco se encontraron asociadas a materiales culturales (K. Borrazzo com. pers. 2015). Vale destacar que este argumento basado en la ausencia de materiales arqueológicos en las depresiones asume que en el interior de las chozas o paravientos Selk'nam se debieron depositar más cantidad de restos culturales. De hecho, este supuesto fue el que condujo a Massone et al. (1993) a realizar una excavación circular en una de las depresiones.

2- El registro arqueológico dentro de las depresiones. En la presente investigación no se registraron diferencias significativas entre la abundancia de registro arqueológico en las depresiones y zonas adyacentes a ellas. De todas formas, la abundancia de huesos, artefactos líticos y otros componentes no deberían ser un criterio fundamental en tanto que las depresiones actúan como trampas naturales y es esperable que en ellas se estabilicen los materiales depositados en distintas posiciones del talud (Favier Dubois, 1998; Martin \& Borella, 1999; Borrero, 2003; Martin, 2006), en especial los de mayor masa debido a que los mismos tienen un mayor potencial de vencer la fuerza de rozamiento de la cobertura vegetal. De igual modo, los cambios vegetacionales observados al interior de las depresiones deberían ser interpretados en primer lugar como consecuencia de la mayor humedad que eventualmente concentran estos rasgos, antes que como producto del enriquecimiento orgánico de actividad humana (Massone et al. 1993).

3- Evidencias de combustión. Los análisis de susceptibilidad magnética indicaron un enriquecimiento de la señal en toda el área de mayor densidad de materiales arqueológicos, independientemente de si se trate de las depresiones o de las zonas adyacentes a las mismas. Pese a que esta evaluación es preliminar, estos datos estarian señalando que efectivamente las poblaciones humanas que ocuparon este espacio llevaron a cabo actividades vinculadas a la combustión o al descarte de materia orgánica, pero no de manera selectiva, es decir, sólo dentro de las depresiones (Dalan \& Banerjee, 1998).

4- Topografía. Por último, resta agregar que no sería esperable el establecimiento de chozas en pendientes que alcanzan los $18^{\circ}$, aunque este no es el caso de todas las depresiones. Asimismo, tampoco se esperaría la instalación de chozas o paravientos en el flanco oeste del cerro, de cara a los vientos del oeste, a pesar de que hay momentos en los que el viento cesa o incluso sopla del cuadrante noreste/ norte. Finalmente, cabe destacar aquí que en las descripciones etnográficas para este sector de estepas septentrionales de la Isla, el formato de vivienda al que se hace referencia es el de paravientos y no el de chozas circulares que son más descriptas para la faja ecotonal/ boscosa de la Isla (Gusinde, 1982[1931]).

\section{Depresiones naturales}

Los distintos estudios llevados a cabo en esta investigación (análisis geomorfológicos, estudios granulométricos, observaciones macroscópicas de perfiles ubicados en distintas posiciones del talud, micromorfología de suelos, cuantificación mineralógica, geoquímica y susceptibilidad magnética) estuvieron dirigidos a buscar propiedades específicas, dentro y fuera de estas depresiones circulares, que pudieran ser explicadas por algunos de los procesos o agentes que tienen lugar (o han tenido lugar en el pasado) en el área del Cerro de los Onas.

Las diferencias físicas entre las depresiones y las zonas adyacentes son poco acentuadas. Esto estaría indicando que los procesos que originaron estos rasgos no dejaron una señal identificable con la metodología utilizada aquí, o bien, que dicha señal fue obliterada por procesos más recientes, 
homogeneizando las propiedades estudiadas dentro y fuera de las depresiones (Bertran \& Texier, 1999).

Sin embargo, en términos generales los estudios granulométricos indican que los sondeos en las depresiones presentan curvas de normales a agudas/ leptocúrticas, es decir, asociadas al predominio de pocos agentes de sedimentación y/o agentes de alta selección. Por otro lado, en las áreas adyacentes a las depresiones, las curvas tienden a ser de normales a aplanadas/platicúrticas, distribución usualmente vinculada a una mezcla de agentes de sedimentación y/o agentes de baja selección. Consistentemente, la fracción de grava en las depresiones es levemente menor que en las zonas adyacentes, donde además la proporción de grava tiende a aumentar en profundidad. Estos resultados no responden a la expectativa de registrar mayor abundancia de material grueso dentro de las depresiones, por ser estas superficies negativas con mayor potencial de entrampamiento. Sin embargo, una interpretación más robusta de los resultados granulométricos requerirá de un muestreo más amplio y un diseño de trabajo experimental dirigido a evaluar la relación entre fracción granulométrica, microtopografía y agente predominante de sedimentación.

El hecho de que en distintas regiones estas depresiones aparezcan en situación de talud invita a pensar la existencia de algún proceso vinculado a la pendiente que pueda generar tales rasgos. La disolución subsuperficial diferencial en forma de oquedades de la roca de caja podría ser una explicación (Goldberg \& Macphail, 2006), pero esto sería más esperable en rocas carbonáticas y tampoco estaría explicando la existencia de depresiones en laderas de valles fluviales como las de Laguna Cañadón Piedra mencionadas arriba.

Vilas et al. (1999) mencionan -aunque en sectores no asociados a pendientes- hoyos formados a partir de arbustos que se vuelan. Una vez que la cubierta vegetal desaparece, el viento profundiza y amplía los hoyos, que luego se llenan de agua y son el origen de muchas de las lagunas estacionales del sector noreste de la Isla. Sin embargo, en el talud de TA, hay depresiones a lo largo del talud y sobre depósitos de pocos centímetros de profundidad hasta alcanzar la roca de caja. La pendiente y los sustratos someros podrían promover una baja capacidad de retención de agua, complejizando el enraizamiento de grandes matas. Adicionalmente, los análisis micromorfológicos y las propiedades macroscópicas de los perfiles no presentan propiedades vinculadas con el estancamiento de un cuerpo de agua, ni con el paso de agua sin cubierta vegetal (Courty et al. 1989; Macphail \& Goldberg, 1990; Goldberg \& Macphail, 2006), aunque procesos posteriores podrían haber borrado la señal. La hipótesis de las matas no puede descartarse por ahora ya que la ausencia de rasgos vinculados al estancamiento de agua no es suficiente, no sólo por obliteración posterior, si no porque el proceso descripto por Vilas et al. (1999) pudo implicar muerte del arbusto y deflación, pero sin la incorporación de agua. Al respecto resta agregar que las fotografías publicadas por Massone et al. (1993) muestran una mayor abundancia de arbustos respecto a lo que se observa en la actualidad.

Otra explicación alternativa es que las depresiones circulares podrían haber sido revolcaderos de animales (Fig. 8), que al ser abandonados se cubrieron nuevamente de vegetación. Tanto las ovejas como los guanacos producen revolcaderos, es decir, áreas de uso recurrente que luego de un lapso temporal quedan desprovistas de vegetación, en topografía levemente negativa y circular/ subcircular. Para el caso de los guanacos, este comportamiento se debe a que su vellón posee muy poca grasa y por tanto necesitan incorporar polvillo inerte para mantener las fibras sin apelmazarse (con electricidad estática) y a su vez expulsar ectoparásitos, tal como lo hacen las gallinas cuando se revuelcan en ceniza o tierra (C. Nuevo com. pers. 2015). El tamaño de las depresiones de TA es similar a los revolcaderos de guanaco (Fig. 8A, B, C, D, E), pero su abundancia y distribución se asemeja a la de las ovejas (Fig. 8F). En la costa oeste de Río Negro se alcanzaron a ver al menos tres revolcaderos de guanaco en un área aproximada de 50x50 m (F. Scartascini com. pers. 2015).

En futuras investigaciones de tipo actualístico, la observación longitudinal y muestreo de revolcaderos se beneficiaría de la evaluación de variables tales como: relación geomorfológica, situación topográfica, orientación respecto a la dirección del viento predominante (en caso que estén sobre taludes), morfometría, características sedimentarias dentro y fuera de los rasgos, análisis geoquímicos y de microvestigios dentro y fuera de los rasgos, tipo y abundancia de cobertura 

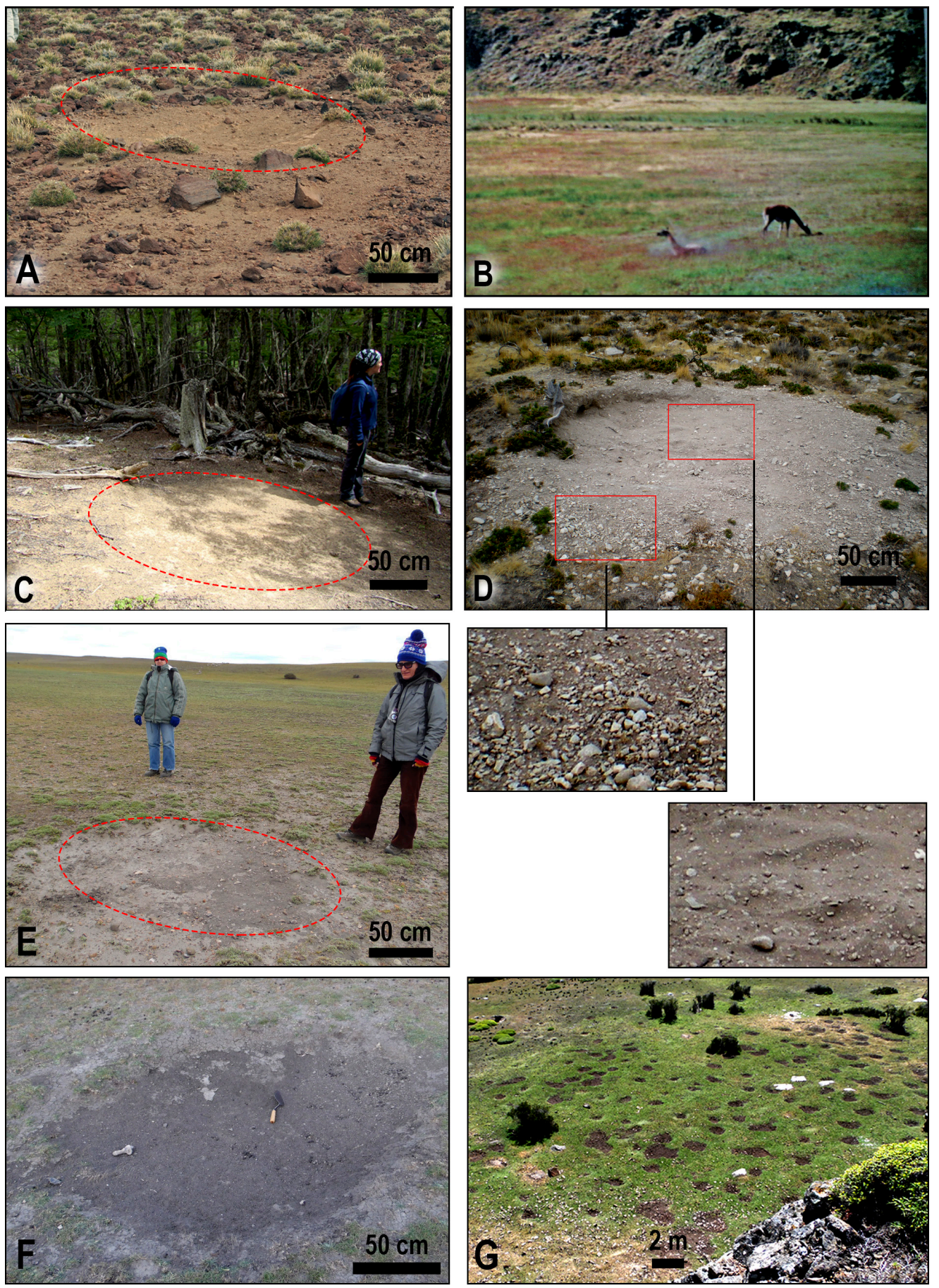

Fig. 8. A. Revolcadero de guanaco en meseta del lago Buenos Aires, Santa Cruz, Argentina (Fotografía: M. Rocco). B. Guanaco en revolcadero en curso superior del río Chacabuco, Aisén, Chile (Fotografía: V. Fernández). C. Revolcadero en un cerro del borde norte del lago Blanco, Chile (Fotografía: L. Borrero). D. Revolcadero en la costa oeste de Rio Negro, Argentina, nótese cómo la acción del animal desplazó las fracciones más gruesas hacia la periferia de la depresión (Fotografía: M. Cardillo). E y F. Revolcaderos en Pali Aike, Santa Cruz (Fotografía: I. Ozán). G. Vista de más de 50 revolcaderos de oveja sobre una pendiente en Cueva de la Vieja, Aisén, Chile, con variaciones que van de 0,7 a 2,7 metros y morfologías en forma de arco con una profundidad de entre 9-20 cm (Fotografía: I. Ozán). 
vegetal, grado de compactación del sustrato, micromorfología, distribución/ abundancia de revolcaderos por área, tiempo de utilización de acuerdo a la especie (guanaco, oveja, etc.) y forma y velocidad de obliteración del rasgo tras el abandono.

\section{CONCLUSIÓN}

Desde un enfoque geoarqueológico, en este trabajo se argumentó que las numerosas depresiones circulares observadas en el talud de TA son de origen natural, hecho que no invalida que algunas de ellas hayan sido utilizadas como base para la instalación de paravientos. El carácter natural de las depresiones se postula en base a: 1) la ausencia de diferencias en el tipo y frecuencia de materiales antrópicos dentro y fuera de estos rasgos; 2) la existencia de depresiones sin materiales antrópicos en el talud de TA y en otras regiones del norte de la Isla; y 3) los mayores valores de susceptibilidad magnética registrados en toda el área de mayor concentración de materiales, independientemente de si se trate de sectores dentro o fuera delas depresiones. Los indicadores sedimentarios y micromorfológicos tampoco mostraron contrastes acentuados dentro y fuera de las depresiones, sólo pequeñas diferencias en la porosidad y presencia de grava. Esto podría deberse a que el proceso que les dio origen pudo haber tenido lugar hace un tiempo relativamente largo y, en efecto, los factores actuales habrían homogeneizado las propiedades. Como explicación alternativa, se postuló que el origen de las depresiones podría estar relacionado con los ya descriptos procesos de deflación eólica tras la muerte de arbustos; o bien, con revolcaderos de guanacos y/u ovejas, cuyas dimensiones, distribución espacial, morfologías y abundancia actual se asemejan al patrón de depresiones observado en el talud de TA. Queda para futuras agendas de investigación contrastar con trabajos experimentales las expectativas sedimentológicas y micromorfológicas esperables tanto para los procesos asociados a la deflación por muerte de matas/ arbustos como para los revolcaderos activos y abandonados.

\section{AGRADECIMIENTOS}

Agradecemos a Flavia Morello, Cecilia Pallo, Manuel San Román y Fabiana Martin por la ayuda brindada durante el trabajo de campo, así como también a Mauricio Massone por su apoyo. También a Charles French y Tonko Rajkovaca por su colaboración en la preparación y análisis de las muestras estudiadas.

\section{BIBLIOGRAFÍA}

Allué, C., Arranz, J., Bava, J., Beneitez, J., Collado, L., \& García-López, J. (2010). Caracterización y cartografía fitoclimáticas del bosque nativo subantártico en la Isla Grande de Tierra del Fuego (Patagonia, Argentina). Forest Systems, 19(2), 189-207.

Arroyo, M., \& Jackson, D. (1998). Paleoindio y fuego en el sitio Tres Arroyos, Tierra del Fuego. Hombre temprano y paleoambiente en Tierra del Fuego. Informe de Avance Proyecto FONDECYT 1960027. Ms.

Bertran, P., \& Texier, P. (1999). Sedimentation processes and facies on a semi-vegetated talus, Lousteau, southwestern France. Earth Surface Processes and Landforms, 24, 177-187.

Birkeland, P. (1999). Soils and Geomorphology. 3ra. Edición, Oxford University Press, Oxford.

Borrazzo, K. (2014). De rocas e instrumentos. La tecnología lítica de los fueguinos septentrionales. En J. Oría \& A. Tívoli (Eds.), Cazadores de mar y de tierra, estudios recientes en arqueología fueguina, (pp. 269-288). Ushuaia: Museo del fin del mundo.

Borrero, L. A. (2000). Ten Years After: esquema para una tafonomía regional de la Patagonia Meridional y norte de Tierra del Fuego. Desde el país de los gigantes. Perspectivas arqueológicas en Patagonia. Tomo I (pp. 183-193). Río Gallegos: Universidad Nacional de la Patagonia Austral.

Borrero, L. A. (2003). Taphonomy of the Tres Arroyos 1 Rockshelter, Tierra del Fuego, Chile. Quaternary International, 109/110, 87-93.

Borrero, L. A., Martin, F., Horwitz, V., Franco, N., Favier Dubois, C., Carballo Marina, F.,... \& Borrazzo, K. (2006). Arqueología de la costa norte de Tierra del Fuego. En I. Cruz \& M. S. Caracotche (Eds.), Arqueología de la costa patagónica Perspectivas para la conservación (pp. 250-264). Rio Gallegos: Universidad Nacional de la Patagonia Austral.

Bullock, P., Fedoroff, N., Jongerius, A., Stoops, G., \& Tursina, T. (1985). Handbook for Soil Thin Section Description. Waine Research Publications, Wolverhampton.

Coronato, A. (2014). Territorios fueguinos: fisonomía, origen, evolución. En J. Oría \& A. Tívoli (Eds.), Cazadores de mar y de tierra, estudios recientes en arqueología 
fueguina, (pp. 43-63). Ushuaia: Museo del fin del mundo.

Coronato, F., \& Bisigato, A. (1998). A temperature pattern classification in Patagonia. International Journal of Climatology, 18, 765-773.

Courty, M. A., Goldberg, P., \& Macphail, R. (1989). Soils and micromorphology in archaeology. Cambridge University Press, Cambridge.

Dabbene, R. (1911). Los indigenas de la Tierra del Fuego. Contribución a la etnografía y antropología de los fueguinos. Litografía La Buenos Aires, Buenos Aires.

Dalan, R.A. \& Banerjee, S. (1998). Solving Archaeological Problems Using Techniques of Soil Magnetism. Geoarchaeology, 13(1), 3-36.

Dirección Meteorológica de Chile (2008). Climatología Sinóptica del sur de Chile. Santiago.

Favier Dubois, C. (1998). Dinámica sedimentaria y cambios ambientales en relación al registro arqueológico $y$ tafonómico del Cerro Cabeza de León. Anales del Instituto de la Patagonia, 26, 137-152.

Fitzpatrick, E. A. (1976). An introduction to Soil Science. Second edition. Longman Scientific \& Technical, Essex.

Frederiksen, P. (1988). Soils of Tierra del Fuego, a Satellitebased Land Survey Approach. Folia Geographica Danica, XVIII, 1-159.

French. H. (2007). Hillslope processes and slope evolution. En H. French (Ed.), The periglacial environment (pp. 216-247). Chichester: John Wiley \& Sons, Ltd.

Gallardo, C. R. (1910). Tierra del Fuego. Los Onas. Cabaut y Cía. Editores, Buenos Aires.

Goldberg, P., \& Macphail, R. (2006). Practical and Theoretical Geoarchaeology. Blackwell Scientific, Oxford.

Gusinde, M. (1982) [1931]. Los indios de Tierra del Fuego. Los Selkinam, Tomo $1^{\circ}$ Volumen I. Centro Argentino de Etnología Americana, Buenos Aires

Horwitz, V. (1995). Ocupaciones prehistóricas en el sur de Bahía San Sebastián (Tierra del Fuego, Argentina). Arqueología, 5, 105-136.

Laming-Emperaire, A., Lavallee, A., \& Humbert, R. (1972). Le site Marazzi en Terre du Feu. Objets et Mondes, XII(2), 225-244.

Macphail, R., \& Goldberg, P. (1990). The micromorphology of tree subsoil hollows: their significance to soil science and archaeology. En L.A. Douglas (Ed.), SoilMicromorphology: A Basic and Applied Science (pp. 425-429). Amsterdam: Developments in Soil Science - Elsevier.

Martin, F. M. (2006). Carnívoros y huesos humanos de
Fuego-Patagonia. Aportes de la tafonomía forense. Sociedad Argentina de Antropología, Buenos Aires.

Martin, F. M., \& Borella, F. (1999). Tafonomía de Tierra del Fuego: reevaluación de la arqueología de Cabeza de León. En Actas de las III Jornadas de Arqueología de la Patagonia, Soplando en el Viento (pp. 439450). Neuquén- Buenos Aires: Instituto Nacional de Antropología y Pensamiento Latinoamericano y Universidad Nacional del Comahue.

Martin, F. M., Barberena, R., \& Guichón, R. (2004). Erosión y huesos humanos. El caso de la localidad Chorrillos, Tierra del Fuego. Magallania, 32, 125-142.

Massone, M. (1997). Prospección arqueológica del sector comprendido entre los ríos Marazzi y Torcido, zona norte de Tierra del Fuego. Anales del Instituto de la Patagonia, 25, 123-136.

Massone, M. (2004). Los cazadores después del hielo. Dirección de Bibliotecas, Archivos y Museos, Santiago.

Massone, M. \& Torres, J. (2004). Pesas, peces y restos de cetáceos en el campamento de Punta Catalina 3 (2.300 años AP). Magallania, 32, 143-161.

Massone, M., \& Morello, F. (2007). Los cetáceos en el mundo Selk’nam: una evaluación arqueológica. En F. Morello, M. Martinic, A. Prieto \& G. Bahamonde (Eds.), Arqueología de Fuego-Patagonia: levantando piedras, desenterrando huesos... y develando arcanos (pp. 709-721). Punta Arenas: Ediciones CeQua.

Massone, M., Jackson, D., \& Prieto, A. (1993). Perspectiva Arqueológica de los Selk'nam. Centro Diego Barros Arana, Santiago.

Massone, M., Morello, F., Prieto, A., San Román, M., Martin, F., \& Cárdenas, P. (2003). Sitios arqueológicos, restos de cetáceos y territorios locales Selk'nam en Bahía Inútil, Tierra del Fuego. Magallania, 31, 45-59.

Miller, C. E., Conard, N., Goldberg. P., \& Berna, F. (2010). Dumping, sweeping and trampling: experimental micromorphological analysis of anthropogenically modified combustion features. P@lethonology, bilingual review of prehistory, 2, 25-37.

Morello, F., Contreras, L., \& San Román, M. (1999). La localidad de Marazzi y el sitio arqueológico Marazzi 1, una re-evaluación. Anales del Instituto de la Patagonia, 27, 183-197.

Morello, F., L. Contreras, L., \& San Román, M., Martinez, I., Martin, F., \& Bahamondes, M. (2005). El sitio Punta Baxa 7, Primera Angostura, Tierra del Fuego. Proyecto FONDECYT 1020004. Ms.

Morello, F., Torres, J., Martinez, I., Rodriguez, K., ArroyoKalin, M., French, C., \& San Román, M. (2012). 
Arqueología de la Punta Santa Ana: reconstrucción de secuencias de ocupación de cazadores-recolectores marinos del estrecho de Magallanes, Patagonia austral, Chile. Magallania, 40(2), 129-149.

Oría, J. (2014). Tierra adentro. Distribuciones artefactuales y movilidad en la estepa fueguina. En J. Oría \& A. Tívoli (Eds.), Cazadores de mar y de tierra, estudios recientes en arqueología fueguina, (pp. 289-312). Ushuaia: Museo del fin del mundo.

Ozán, I. L., French, C., Morello Repetto, F., Vásquez, C., \& Luppo, T. (2015). Coastal occupations in Tierra del Fuego, southernmost South America: a geoarchaeological study of a Late Holocene huntergatherer context at Marazzi 2. Geoarchaeology, 30(6), 465-482.

Pallo, M. C. (2012). El estrés invernal como generador de áreas marginales en Patagonia meridional durante el Holoceno tardío. Comechingonia Virtual, VI(1), 86114.

Pisano, E. (1977). Fitogeografía de Fuego-Patagonia chilena. I-Comunidades vegetales entre las latitudes 52 y $56^{\circ}$ S. Anales del Instituto de la Patagonia, 8, 121-250.

Prevosti, F. J. (2006). New material of Pleistocene cats (Carnivora Felidae) from Southern South America with comments on biogeography and the fossil record. Geobios, 39, 649-679.

Prieto, A., Martín, F. M., \& Arroyo, M. (1997). Excavaciones del sitio TA-14(30). Informe FONDECYT 1960027. Ms.

Prieto, A., Cárdenas, P., Bahamonde, G., \& Massone, M. (2004). Hallazgo de una fuente de materia prima en el chorrillo Miraflores, Tierra del Fuego, Chile. Magallania, 32, 229-232.
Saxon, E. (1976). La Prehistoria de Fuego-Patagonia: colonización de un hábitat marginal. Anales del Instituto de la Patagonia, 7, 63-73.

Soil Survey Staff (1999). Soil Taxonomy. A Basic System of Soil Classification for Making and Interpreting Soil Surveys. United States Department of Agriculture Natural Resources Conservation Service, Washington, DC.

Stoops, G. (1986). The future of micropedology. Pedologie, $36,225-233$

Stoops, G. (2003). Guidelines for Analysis and Description of Soil and Regolith Thin Sections, first ed. Soil Science Society of America Inc., Madison.

Stoops, G., Marcelino, V., \& Mees, F. (2010). Interpretation of Micromorphological features of soil and regoliths. Elsevier, Amsterdam.

Torres, J. (2009). Resultados preliminares del análisis de bolas líticas y los procesos de manufactura en contextos de cazadores-recolectores terrestres del norte de Tierra del Fuego. En M. Salemme, F. Santiago, M. Álvarez, E. Piana, M. Vázquez \& M. Mansur (Eds.), Arqueología de Patagonia: Una mirada desde el último confín (pp. 393-411). Ushuaia: Editorial Utopías.

Vilas, F., Arche, A., Ferrero, M., Bujalesky, G., Isla, F., \& González Bonorino, G. (1986-1987). Sedimentación intermareal en Bahía San Sebastián, Tierra del Fuego, Argentina. Acta Geológica Hispánica, 21/-22, 253260.

Vilas, F., Arche, A., Ferrero, M., \& Isla, F. (1999). Subantarctic macrotidal flats, cheniers and beaches in San Sebastian Bay, Tierra del Fuego, Argentina. Marine Geology, 160, 301-326. 


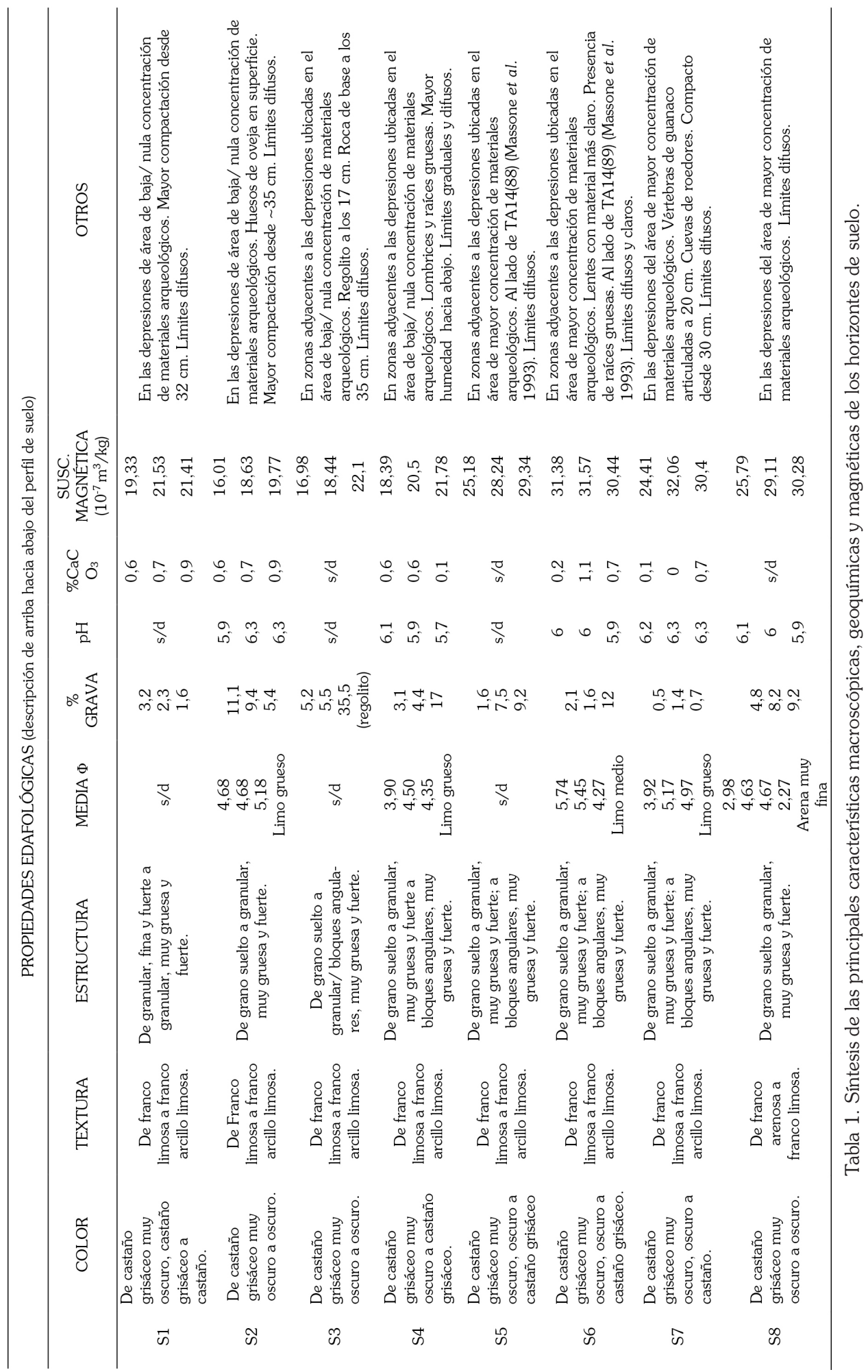




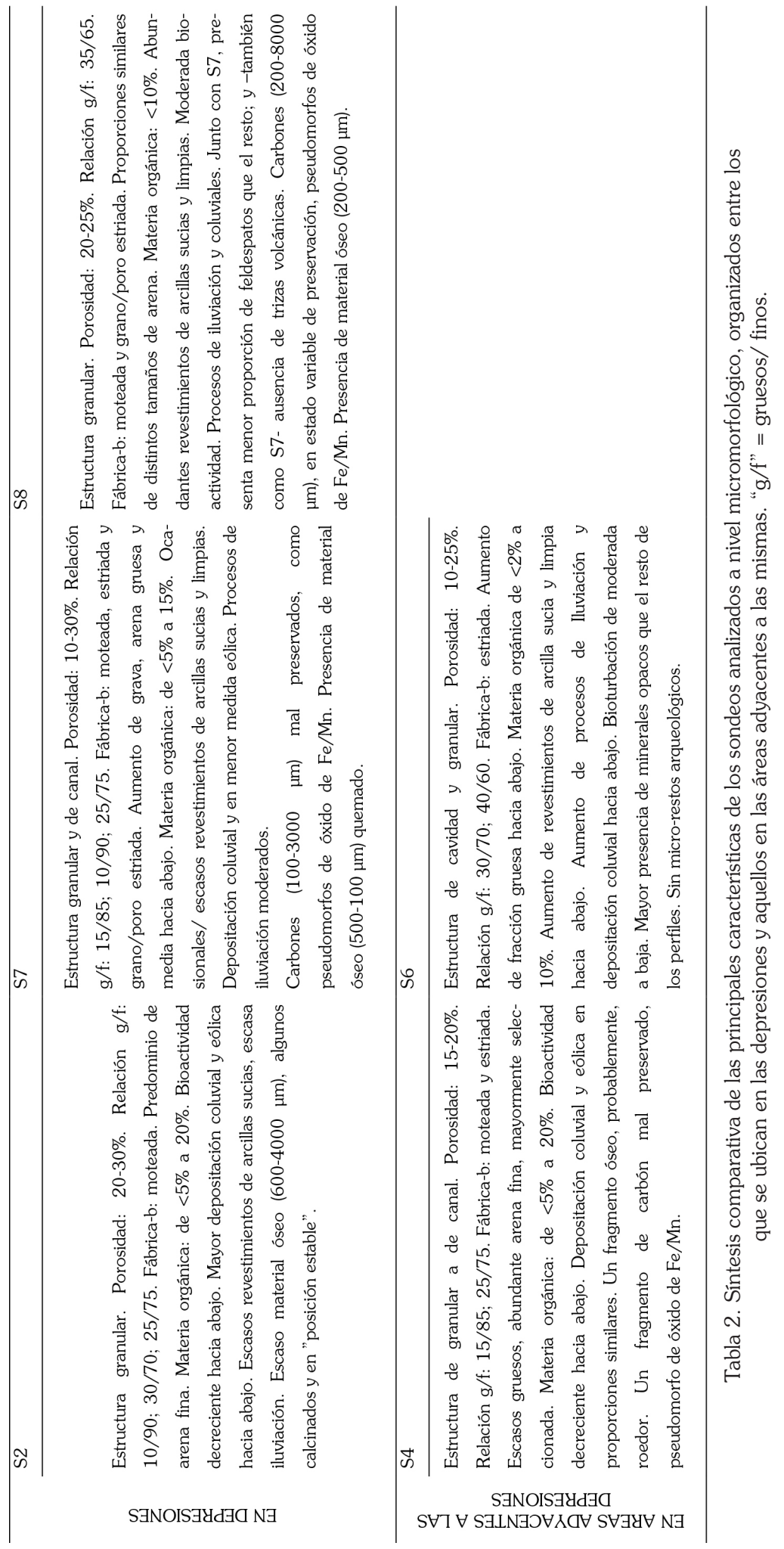


